\title{
Selective hydrogenation of diphenylacetylene using NiCo nanoparticles supported on mesoporous carbon as catalyst
}

\author{
Alyaa S. SHIDDIQAH ${ }^{1}$, Iman ABDULLAH ${ }^{1}{ }^{\star}\left(\mathbb{D}\right.$, Yuni K. KRISNANDI ${ }^{1,2}$ (D) \\ ${ }^{1}$ Department of Chemistry, Faculty of Mathematics and Natural Sciences, University of Indonesia, Depok, Indonesia \\ ${ }^{2}$ Solid Inorganic Framework Laboratory, Department of Chemistry, Faculty of Mathematics and Natural Sciences, \\ University of Indonesia, Depok, Indonesia
}

Received: 08.09.2021

- Accepted/Published Online: 30.11.2021

$\bullet$

Final Version: 16.06.2022

\begin{abstract}
Hydrogenation of alkynes to alkenes is an important procedure in the synthesis of organic compounds. In this study, selective hydrogenation was carried out on diphenylacetylene as a model of alkyne compounds using $\mathrm{NaBH}_{4}$ as a hydrogen source and $\mathrm{NiCo}$ bimetallic nanoparticles supported on mesoporous carbon $(\mathrm{NiCo} / \mathrm{MC})$ as a catalyst. The mesoporous carbon was prepared using the soft-templated method from phloroglucinol and formaldehyde as precursors while the $\mathrm{NiCo} / \mathrm{MC}$ catalyst was synthesized using a wet impregnation method. Based on surface area analysis, it was found that the pore diameters of $\mathrm{MC}, \mathrm{Ni} / \mathrm{MC}$, and $\mathrm{NiCo} / \mathrm{MC}$ were $12.8 \mathrm{~nm}$, $13.4 \mathrm{~nm}$, and $12.7 \mathrm{~nm}$ respectively, which indicated the mesoporous size of the materials. TEM analysis also confirmed the formation of nanoparticles on mesoporous carbon with the average size similar to the pore structure of the support, thus indicating the incorporation of the metals on the support. The hydrogenation reaction of diphenylacetylene was carried out with variations in reaction time and temperature. GCMS analysis of the products showed that the optimum conditions were obtained over $\mathrm{NiCo} / \mathrm{MC}$ catalyst at $50{ }^{\circ} \mathrm{C}$ for 4 $\mathrm{h}$ with a diphenylacetylene conversion of $71.5 \%$ and a selectivity of $87.1 \%$ for the formation of cis-stilbene.
\end{abstract}

Key words: mesoporous carbon, NiCo catalyst, diphenylacetylene, selective hydrogenation

\section{Introduction}

The reduction and isomerization of alkyne compounds are important in organic synthesis [1]. In general, frequently used methods to reduce alkyne are direct hydrogenation with molecular hydrogen and transfer hydrogenation. The advantages of transfer hydrogenation are that it does not use flammable compressed $\mathrm{H}_{2}$ gas, hydrogen donors are easier to handle, easy for the recycling of side-products, and more inexpensive [2]. Therefore, solid compounds that can release hydrogen are used, for example, sodium borohydride or $\mathrm{NaBH}_{4}$ [3]. Although hydrogenation with $\mathrm{NaBH}_{4}$ is slow, the process can be accelerated in the presence of a catalyst. Examples of reported methods related to alkynes hydrogenation using $\mathrm{NaBH}_{4}$ as reducing agents using homogeneous catalysts are hydrogenation of styrene to ethyl-benzene using bimetallic $\mathrm{Ni}$ (II) complex, and hydrogenation of alkynes using colloidal nickel nanoparticles [2, 4, 5].

Nickel as a catalyst for transfer hydrogenation of alkyne compounds has several advantages, namely, it is relatively inexpensive, abundant, and environmentally friendly [2]. Nickel itself has long been known to have a good affinity for hydrogen and thus, serves as a good catalyst in the hydrogenation of unsaturated bonds. However, nickel alone sometimes is not sufficient to give high catalytic activity and selectivity, especially when used in the form of heterogeneous catalysts. On the other hand, the catalytic property of nickel can be enhanced by modification with other metals in the form of bimetallic Ni-M. Various nickel based-bimetallic catalysts have been reported to be successfully synthesized for various applications such as $\mathrm{Ni}-\mathrm{Fe}$ as a catalyst for hydrogen generation from sodium borohydride [6], Ni-Sn as a catalyst for hydrogenation of 2-methylfuran [7], $\mathrm{Ni}-\mathrm{Cu}$ as a catalyst in nitrophenol reduction [8], Ni-Zn as a catalyst in carboxylation with $\mathrm{CO}_{2}$ [9], Ni-Ga as a catalyst in the reduction of $\mathrm{CO}_{2}$ to methanol [10], Ni-Ag as a catalyst in acetylene hydrogenation [11], and some Ni-noble metals for $\mathrm{CO}_{2}$ reforming of methane [12]. Recently, Yang et al [13] reported the use of bimetallic $\mathrm{Ni}-\mathrm{M}(\mathrm{M}=\mathrm{Zn}, \mathrm{Ga}, \mathrm{Cu}$, and $\mathrm{Fe}) / \mathrm{AlSBA}-15$ as a catalyst in the semihydrogenation of phenylacetylene. The results showed that $\mathrm{NiZn}_{3} /$ AlSBA-15 gave the highest styrene selectivity, 90.3\%. Bimetallic $\mathrm{NiCo}$ on $\mathrm{TiO}_{2}$ has also been reported as a promising catalyst for the dehydrogenation of hydrazine hydrate [14].

*Correspondence: iman.abdullah@sci.ui.ac.id 
Meanwhile, mesoporous carbon as catalyst support has attracted great interest because it has a large surface area and pore distribution. Mesoporous carbon is also nontoxic, noncorrosive, environmentally friendly, and can be used repeatedly [15]. Previously, we have reported the utilization of mesoporous carbon as solid support for various nickel species [16-18], bimetallic nickel-zinc [9], and copper [19]. In this report, we present the use of bimetallic NiCo supported on mesoporous carbon $(\mathrm{NiCo} / \mathrm{MC})$ as a catalyst in selective hydrogenation reaction of diphenylacetylene to cis-stilbene with $\mathrm{NaBH}_{4}$ as a hydrogen source/reducing agent. The hydrogenation reactions were carried out at variations in time and temperature to determine the optimum conditions. The catalytic activity of $\mathrm{NiCo} / \mathrm{MC}$ was also compared to the common monometallic $\mathrm{Ni} / \mathrm{MC}$ for the same reaction to investigate the role of the second metal (Co) on the catalytic reaction.

\section{Materials and methods}

\subsection{Materials}

The materials used were phloroglucinol 99\% (Sigma Aldrich), pluronic F127 (Sigma Aldrich), ethanol 97\% (Merck), HCl 37\% (J.T Baker), formaldehyde 37\% (Merck), nickel (II) nitrate (Merck), cobalt (II) nitrate (Merck), diphenylacetylene 98\% (Sigma Aldrich), sodium borohydride powder $\geq 98 \%$ (Sigma Aldrich), methanol 99\% (Merck), cis-stilbene 96\% (Sigma Aldrich), $\mathrm{N}_{2}$ gas, $\mathrm{H}_{2}$ gas, and deionized water.

\subsection{Synthesis of catalysts}

\subsubsection{Synthesis of mesoporous carbon}

The mesoporous carbon (MC) was prepared via a soft template method using a standard reported procedure with modifications [20]. The synthesis was started by dissolving $1.25 \mathrm{~g}$ phloroglucinol and $1.25 \mathrm{~g}$ pluronic F-127 in $10 \mathrm{~mL}$ of 9:10 (w/w) ethanol-water mixture. Then $0.08 \mathrm{~mL}$ of $37 \% \mathrm{HCl}$ was added, followed by the addition of $1.25 \mathrm{~mL}$ of $37 \%$ formaldehyde. The solution was stirred for $2 \mathrm{~h}$ until two phases were formed. The bottom layer was taken, then stirred for $12 \mathrm{~h}$, and left for $24 \mathrm{~h}$ at room temperature until a monolith was formed. The monolith was put into an autoclave and heated at $100{ }^{\circ} \mathrm{C}$ in an oven for $24 \mathrm{~h}$. The solid was then carbonized in a tubular furnace with $\mathrm{N}_{2}$ gas flow with a heating rate of $5{ }^{\circ} \mathrm{C} / \mathrm{min}$ at a temperature range of $100-850^{\circ} \mathrm{C}$. The carbonization temperature was maintained at $850{ }^{\circ} \mathrm{C}$ for $2 \mathrm{~h}$.

\subsubsection{Synthesis of $\mathrm{Ni} / \mathrm{MC}$ and $\mathrm{NiCo} / \mathrm{MC}$}

The synthesis of Ni/MC was performed by wet impregnation method. First, a $0.085 \mathrm{M}$ nickel nitrate solution was prepared by dissolving an appropriate amount of nickel nitrate powder in a 1:1 (w/w) water-ethanol mixture. Then, $0.5 \mathrm{~g}$ MC powder was dispersed into the solution by sonication for $10 \mathrm{~min}$, followed by stirring for $48 \mathrm{~h}$ at room temperature, dried in an oven for $6 \mathrm{~h}$ at $100{ }^{\circ} \mathrm{C}$ and finally reduced by $\mathrm{H}_{2}$ gas flow at $400{ }^{\circ} \mathrm{C}$ for $4 \mathrm{~h}$. The synthesis of $\mathrm{NiCo} / \mathrm{MC}$ was prepared by the same method as $\mathrm{Ni} / \mathrm{MC}$ using an equimolar concentration of nickel and cobalt nitrate as precursors. The synthesized catalysts were then characterized using FTIR, XRD, SEM-EDX, TEM, and SAA-BET.

\subsection{Hydrogenation of diphenylacetylene}

Hydrogenation of diphenylacetylene was conducted by dissolving $0.1782 \mathrm{~g}$ diphenylacetylene $(1 \mathrm{mmol})$ in $8 \mathrm{~mL}$ of methanol in a round flask. After stirring for $10 \mathrm{~min}, 0.0757 \mathrm{~g} \mathrm{NaBH}_{4}$ (2 equiv) and $0.0450 \mathrm{~g} \mathrm{Ni} / \mathrm{MC}$ or NiCo/MC was added. The mixture was stirred, and the reaction was carried out for 2,4 , and $6 \mathrm{~h}$, with temperature variations of $30{ }^{\circ} \mathrm{C}$ and $50{ }^{\circ} \mathrm{C}$. The reaction products were characterized using GC-MS.

\section{Results and discussion}

\section{Characterization of catalysts}

Mesoporous carbon was characterized by FTIR to determine the success of carbonization. Figure 1 shows the difference spectrum between mesoporous carbon before and after carbonization. Before the carbonization, it shows the absorption peak around $3200-3600 \mathrm{~cm}^{-1}$ which is the peak of $\mathrm{OH}$ stretching vibration, $2850-3000 \mathrm{~cm}^{-1}$ which is the peak of $\mathrm{CH}$ stretching vibration, and $1600-1700 \mathrm{~cm}^{-1}$ which is the vibrational peak of the $\mathrm{C}=\mathrm{C}$ stretching. The spectrum after carbonization indicates the absence of the absorption peaks, showing that the carbonization process has succeeded in functional groups decomposition of the precursors.

Figure 2 shows the X-Ray diffraction pattern of mesoporous carbon, Ni/MC, and NiCo/MC. X-Ray diffraction pattern of MC shows two peaks at $2 \theta$ of $22.9^{\circ}$ and $43.1^{\circ}$ which are the typical peaks for carbon material according to JCPDS index No.75-1621 [21]. The peaks also indicate that the synthesized mesoporous carbon has an amorphous structure. The diffraction pattern of $\mathrm{Ni} / \mathrm{MC}$ (blue line) shows three additional peaks detected at $44.46^{\circ}, 51.88^{\circ}$, and $76.38^{\circ}$ in addition to the baseline peaks of MC. The additional peaks show the presence of nickel metal in the form of cubic crystals according to JCPDS No. 04-0850 [22]. The diffraction pattern of NiCo/MC shows peaks at $23.42^{\circ}, 34.76^{\circ}, 43.67^{\circ}, 61.54^{\circ}, 75.37^{\circ}$, and $77.00^{\circ}$. According to JCPDS No.15-0806, cobalt metal has three distinctive peaks of diffraction at $44.1^{\circ}, 51.4^{\circ}$, and 


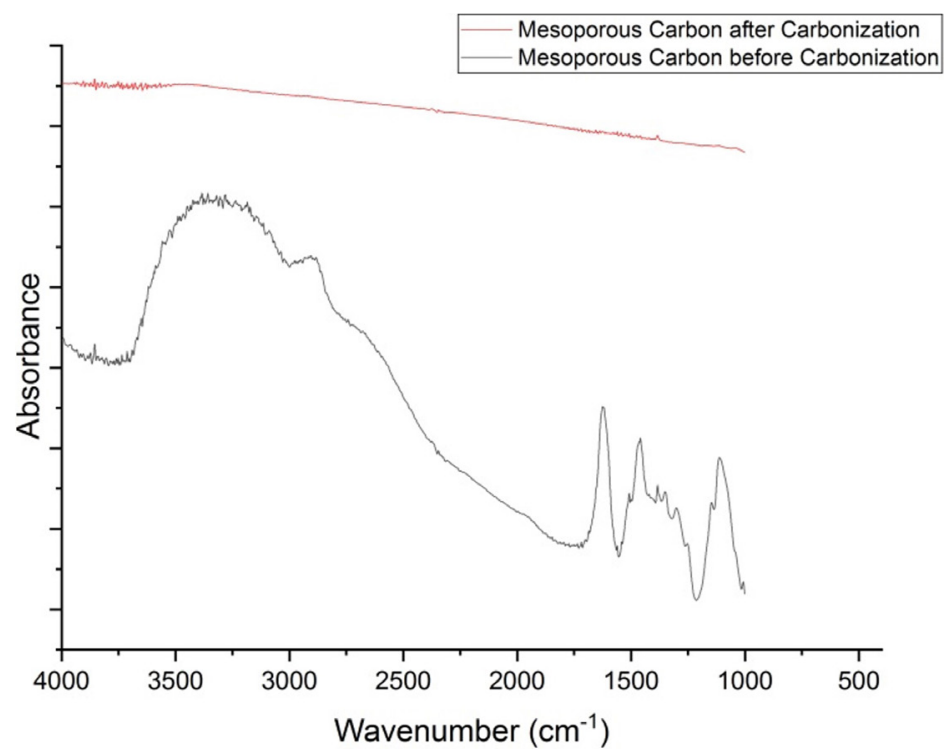

Figure 1. FTIR spectra of mesoporous carbon before and after carbonization.

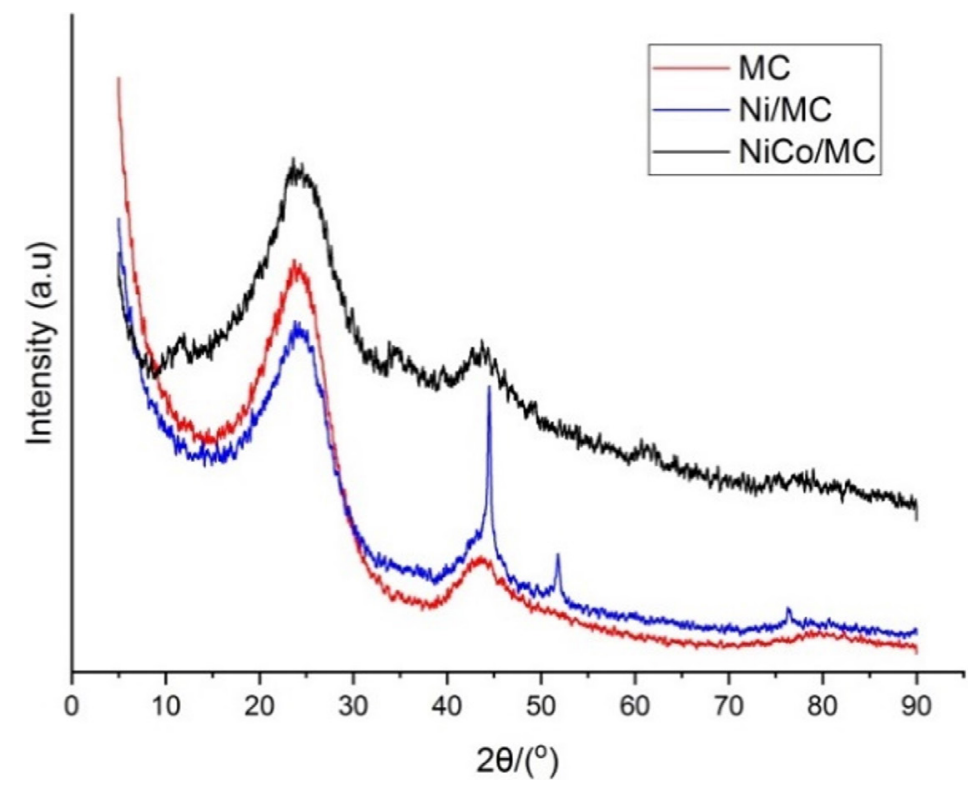

Figure 2. X-Ray diffraction patterns of synthesized mesoporous carbon, Ni/ $\mathrm{MC}$, and $\mathrm{NiCo} / \mathrm{MC}$.

75.9 $9^{\circ}$ while according to JCPDS No. 75-1621, cobalt oxide shows diffraction peaks at 36.5, 42.4, 61.5, 73.5, and 77.5. Therefore, the $\mathrm{NiCo} / \mathrm{MC}$ XRD pattern indicates that in addition to the formation of nickel and cobalt metals, there is also the formation of cobalt oxide on the mesoporous carbon surface.

SEM images of Ni/MC and NiCo/MC are shown in Figure 3a-3h. The figures show the presence of fine grains on the surface of materials. EDX mapping of Ni/MC reveals that the nickel metal is distributed evenly on $\mathrm{MC}$ (Figure $3 \mathrm{~d}$ ). The same result was obtained in $\mathrm{NiCo} / \mathrm{MC}$, both nickel and cobalt metal have been deposited on $\mathrm{MC}$ evenly (Figure $3 \mathrm{~g}$ and $3 \mathrm{~h}$ ). The EDX analysis showed a Ni loading in Ni/MC at $3.7 \%$ by weight. Meanwhile the $\mathrm{Ni}$ and Co content in NiCo/MC is $1.1 \%$ and $1.2 \%$, respectively.

Characterization using transmission electron microscopy (TEM) was used to see the morphology and particle distribution at higher magnification and resolution. Based on Figure 4a, the mesoporous carbon has a spherical pore 

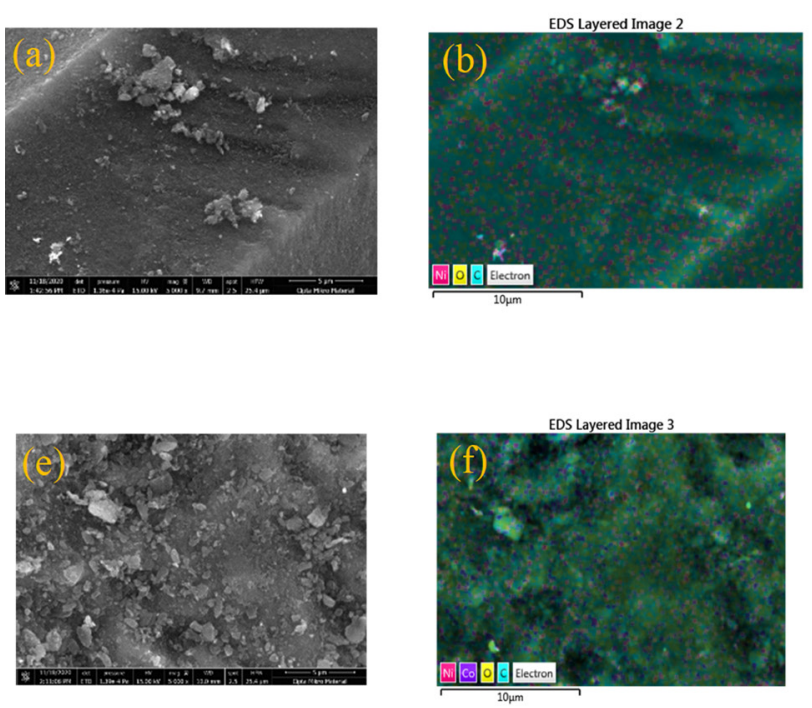

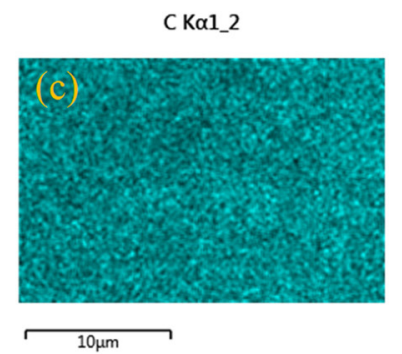

$\mathrm{Ni} \mathrm{K} \alpha 1$

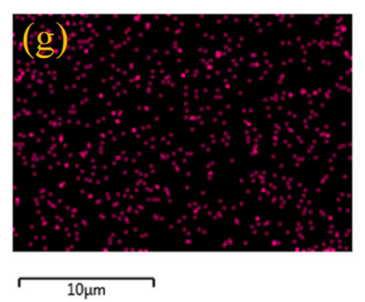

Ni $K \alpha 1$

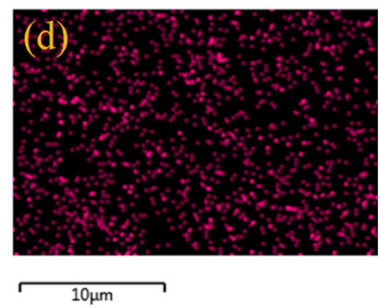

Co K $\alpha 1$

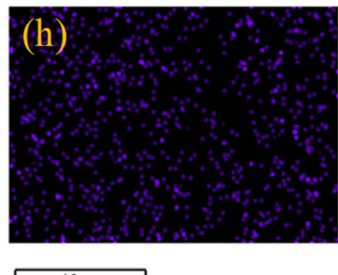

Figure 3. (a) SEM images of Ni/MC; (b) combined elemental mapping image of Ni/MC; (c) carbon mapping image of Ni/MC; (d) nickel mapping image of $\mathrm{Ni} / \mathrm{MC}$; (e) SEM images of $\mathrm{NiCo} / \mathrm{MC}$; (f) combined elemental mapping image of $\mathrm{NiCo} / \mathrm{MC}$; (g) nickel mapping image of $\mathrm{NiCo} / \mathrm{MC}$; (h) cobalt mapping image of $\mathrm{NiCo} / \mathrm{MC}$.
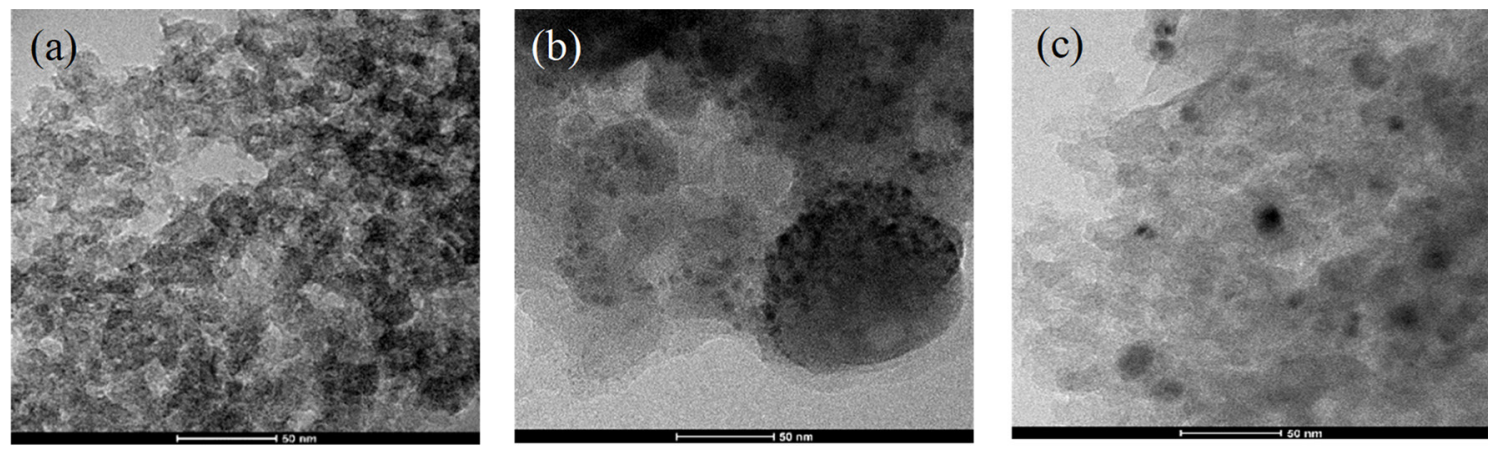

Figure 4. TEM images of (a) mesoporous carbon (b) Ni/MC, and (c) NiCo/MC.

structure that forms a wormhole-like mesoporous channel with a random pore orientation. TEM images of Ni/MC and $\mathrm{NiCo} / \mathrm{MC}$ (Figure $4 \mathrm{~b}$ and Figure $\mathrm{c}$ ) show that nickel and bimetallic nickel-cobalt metals are evenly distributed on mesoporous carbon. Apart from the metal appearance on mesoporous carbon, the porous structure of MC can still be observed around the black metal spot, which indicates that the carbon matrix remains intact after impregnation with metal [23]. ImageJ software was used to determine the diameter and number of pores in mesoporous carbon, as well as the diameter of $\mathrm{Ni}$ and $\mathrm{NiCo}$ nanoparticles on $\mathrm{Ni} / \mathrm{MC}$ and $\mathrm{NiCo} / \mathrm{MC}$. The results are presented in the following histogram (Figure 5). Before impregnation, MC had a pore diameter of $4 \mathrm{~nm}$ to $33 \mathrm{~nm}$ with a dominant pore size of $12.9 \mathrm{~nm}$ (Figure 5a). After impregnation, Ni particles formed in MC have a particle size range of 2.9 to $35 \mathrm{~nm}$, with the dominant particle diameter being $13 \mathrm{~nm}$ (Figure 5b). The same result was observed in the bimetallic NiCo (Figure 5c). These results indicate that in general, the size of the metal particles formed corresponds to the available MC pores, which is in accordance with the role of MC as metal support.

Surface area analysis was used to determine the adsorption-desorption isotherm, surface area and pore distribution of the catalysts. The calculation was carried out using the Brunauer-Emmett-Teller (BET) method to determine the surface area and Barrett-Joyner-Halenda $(\mathrm{BJH})$ method to determine the pore size distribution of the material. Figure 6 shows the isotherm curve of the mesoporous carbon, $\mathrm{Ni} / \mathrm{MC}$ and $\mathrm{NiCo} / \mathrm{MC}$. The mesoporous properties of $\mathrm{MC}$ and its derivatives are confirmed by the IV type of adsorption isotherm curve and $\mathrm{H}-1$ hysteresis loop from all curves. The surface properties of all materials are summarized in Table 1 . Based on the table, Ni/MC has a larger surface area than mesoporous carbon and 
(a)

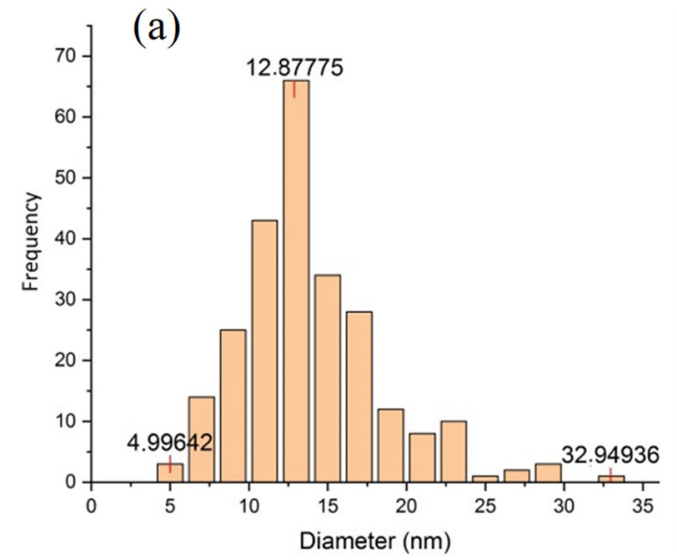

(b)

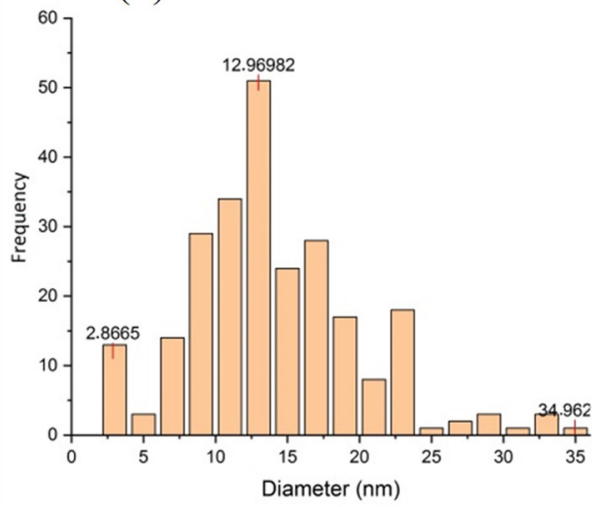

(c)

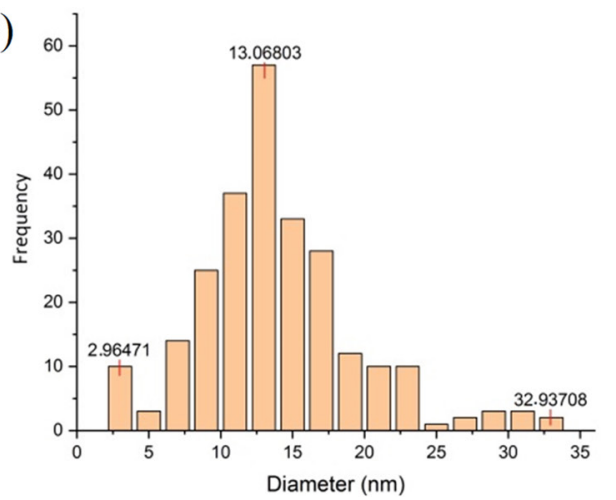

Figure 5. Histogram of pore size distribution of (a) mesoporous carbon, particle diameter of (b) Ni/ $\mathrm{MC}$, and (c) NiCo/MC.

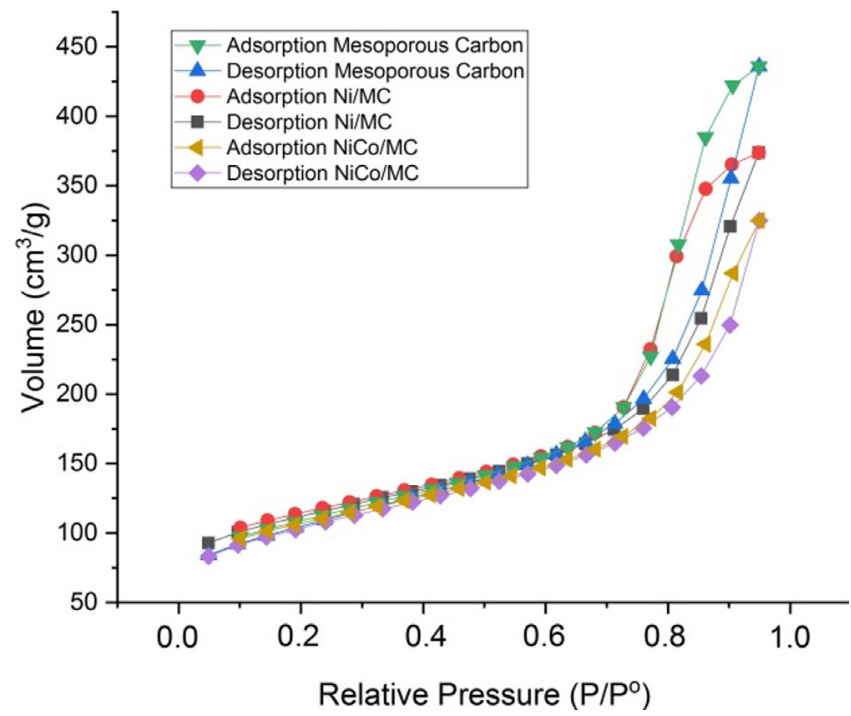

Figure 6. Adsorption-desorption isotherms curve of mesoporous carbon, $\mathrm{Ni} / \mathrm{MC}$, and $\mathrm{NiCo} / \mathrm{MC}$.

$\mathrm{NiCo} / \mathrm{MC}$. This is because the nickel was impregnated not only inside the pore but also on the surface of the mesoporous carbon and formed an aggregate outside the pore, thereby increasing the surface area of the Ni/MC catalyst. This is similar to what we have observed in the impregnation of porous carbon with copper [19]. The pore diameter of MC is relatively the 
same after Ni-impregnation, indicating that the impregnation process did not change the pore structure of the mesoporous carbon. These results support the data obtained from the TEM characterization.

\section{Catalytic test on selective hydrogenation of diphenylacetylene}

The $\mathrm{NiCo} / \mathrm{MC}$ and $\mathrm{Ni} / \mathrm{MC}$ catalyst were tested for their catalytic activity in the hydrogenation reaction of diphenylacetylene with $\mathrm{NaBH}_{4}$ to give stilbene as the product. The unreacted diphenylacetylene and product from hydrogenation reaction were analyzed using GC-MS. Typical chromatograms of the reaction mixtures and MS spectra are presented in Figure 7a and Figure 7b, respectively. The chromatogram in Figure 7a shows the presence of unreacted diphenyleacetylene and both cis- and trans-stilbene as hydrogenated products. Meanwhile, the MS spectrum in Figure $7 \mathrm{~b}$ shows the fragmentation of the peak that appears at a retention time of 9.848 min which is a cis-stilbene compound. Proposed reaction mechanism for the $\mathrm{Ni} / \mathrm{MC}$ - or $\mathrm{NiCo} / \mathrm{MC}$-catalyzed hydrogenation of diphenylacetylene with $\mathrm{NaBH}_{4}$ is presented in Figure 8. The hydrogenation was first initiated with hydrogen transport from borohydride to catalyst surface via adsorption. The nucleophilic $\mathrm{H}$ on the surface of the catalyst would attack the triple bond in alkyne. Next, methanol as a solvent will bind with boron, and the hydrogen-bond becomes weak, resulting in a second protonation in the triple bond of alkynes to afford stilbene. Hydrogenation reactions using $\mathrm{NaBH}_{4}$ and methanol tend to form cis-alkene as a major product since methanol is activated by the adsorbed borohydride, thus the hydrogen source from methanol and $\mathrm{NaBH}_{4}$ will interact with alkyne via syn-hydrogenation manner [4].

First, we investigated the effect of reaction time to diphenylacetylene conversion as well as cis-stilbene selectivity for both $\mathrm{Ni} / \mathrm{MC}$ and $\mathrm{NiCo} / \mathrm{MC}$ catalysts. At this stage, the reaction was conducted at room temperature. Figure 9a shows that both $\mathrm{Ni} / \mathrm{MC}$ and $\mathrm{NiCo} / \mathrm{MC}$ catalysts provide almost the same catalytic activity, in which there is an increase in the conversion of diphenylacetylene with increasing reaction time for both catalysts. Both catalysts also show good selectivity toward the formation of cis-stilbene, especially at a relatively short reaction time. However, with increasing reaction time,

Table 1. Physicochemical properties of Mesoporous Carbon, Ni/MC, and NiCo/MC.

\begin{tabular}{|l|l|l|l|l|l|l|l|}
\hline Sample & $\begin{array}{l}\mathbf{S}_{\text {BET }}^{\text {a }} \\
\left(\mathbf{m}^{2} / \mathbf{g}\right)\end{array}$ & $\begin{array}{l}\mathbf{S}_{\text {ext }}^{\mathbf{b}} \\
\left(\mathbf{m}^{2} / \mathbf{g}\right)\end{array}$ & $\begin{array}{l}\mathbf{S}_{\text {mikro }} \\
\left(\mathbf{m}^{2} / \mathbf{g}\right)\end{array}$ & $\begin{array}{l}\mathbf{V}_{\text {total }} \mathbf{c} \\
(\mathbf{c c / g})\end{array}$ & $\begin{array}{l}\mathbf{V}_{\text {meso }} \mathbf{d} \\
(\mathbf{c c} / \mathbf{g})\end{array}$ & $\begin{array}{l}\mathbf{V}_{\text {micro }} \mathbf{c} \\
(\mathbf{c c} / \mathbf{g})\end{array}$ & $\begin{array}{l}\text { Pore diameter } \\
(\mathbf{n m})\end{array}$ \\
\hline $\mathrm{MC}$ & 360 & 219 & 141 & 0.5459 & 0.5051 & 0.0444 & 12.81 \\
\hline $\mathrm{Ni} / \mathrm{MC}$ & 376 & 220 & 156 & 0.9018 & 0.8577 & 0.0442 & 13.36 \\
\hline $\mathrm{NiCo} / \mathrm{MC}$ & 353 & 219 & 135 & 0.6939 & 0.6492 & 0.0447 & 12.76 \\
\hline
\end{tabular}

a determined using BET method

${ }^{\mathrm{b}}$ determined using t-plot method

c determined using BJH method

${ }^{\mathrm{d}}$ determined by the difference of Vtotal - Vmicro $=$ Vmeso

(a)

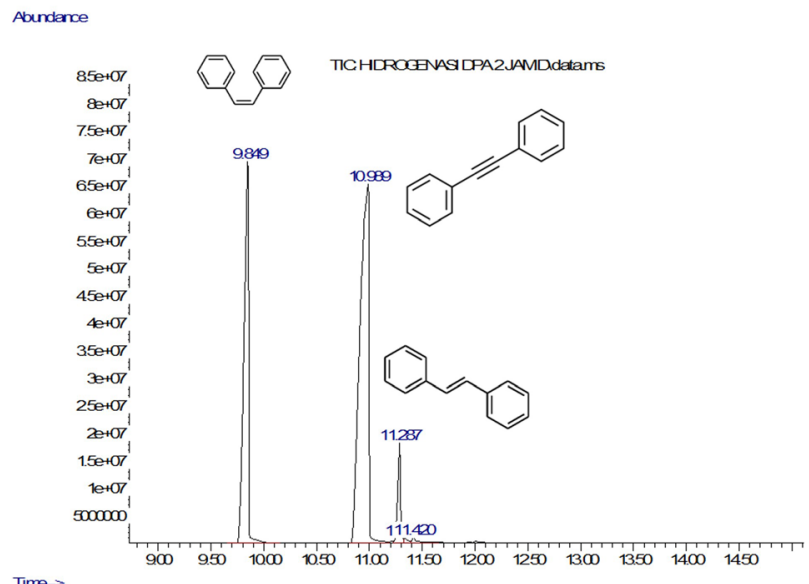

(b)

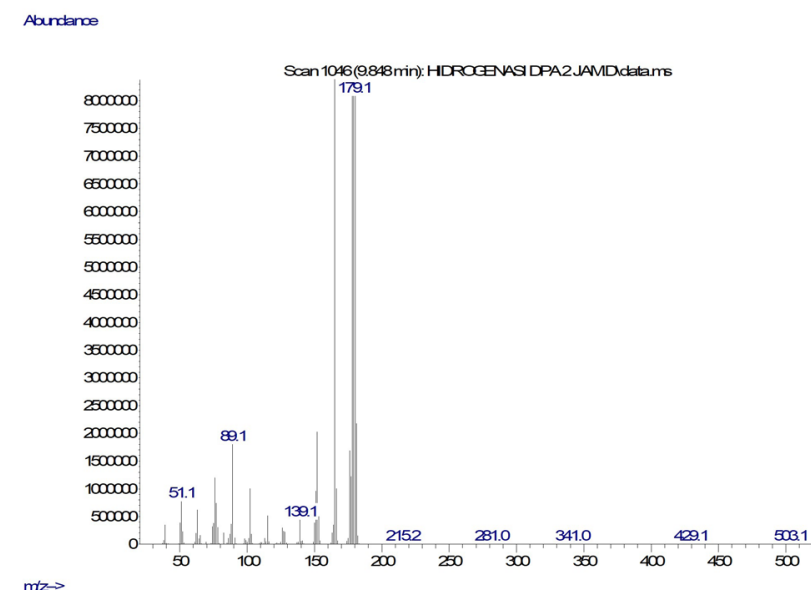

$m z \rightarrow$

Figure 7. (a) Chromatogram of reaction mixtures (reaction conditions: using NiCo/MC catalyst at $30^{\circ} \mathrm{C}$ for $2 \mathrm{~h}$ ), (b) mass spectrum of cis-stilbene. 

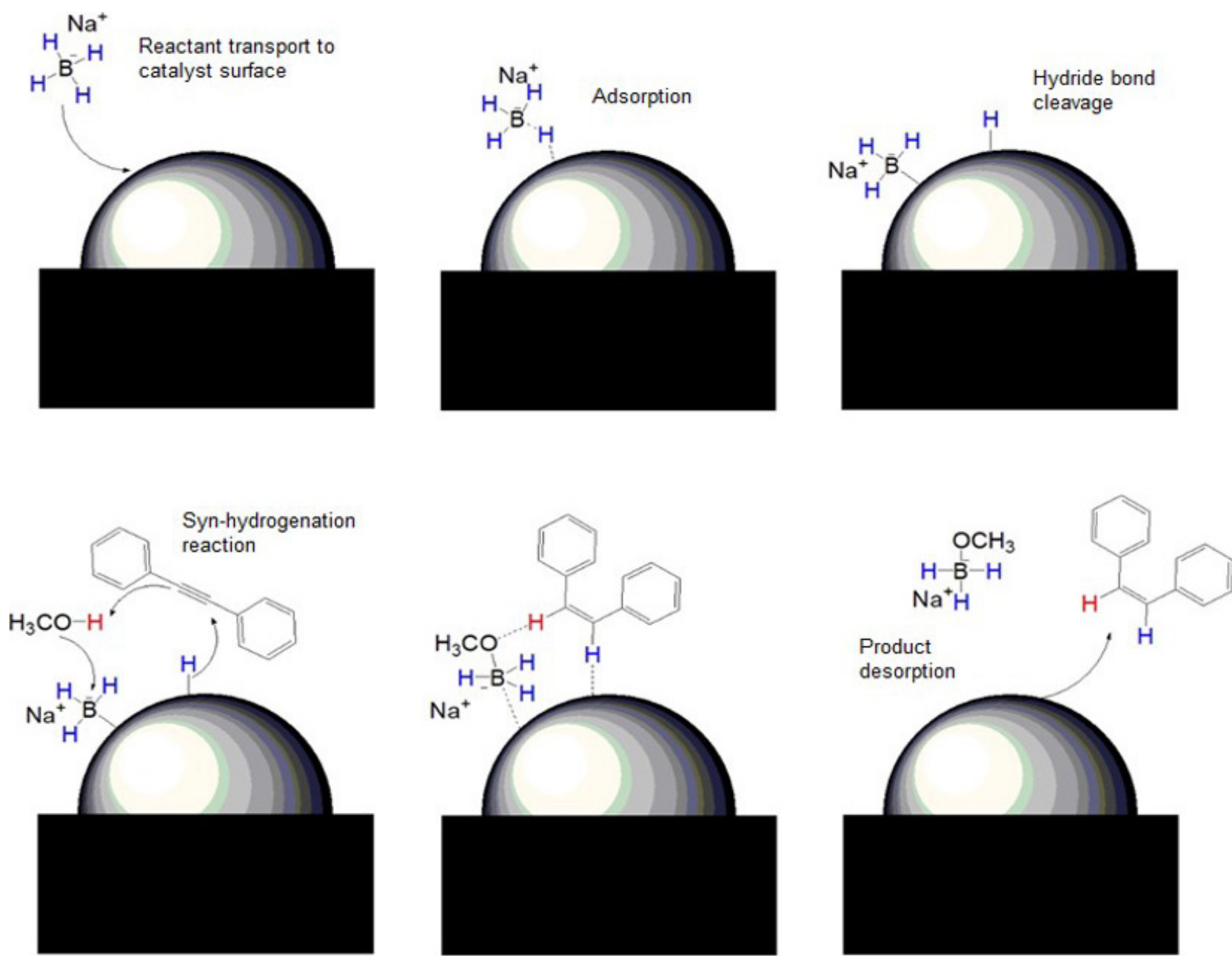

Figure 8. Reaction mechanism for hydrogenation of diphenylacetylene catalyzed by metal (Ni or bimetallic NiCo) supported on MC.

(a)

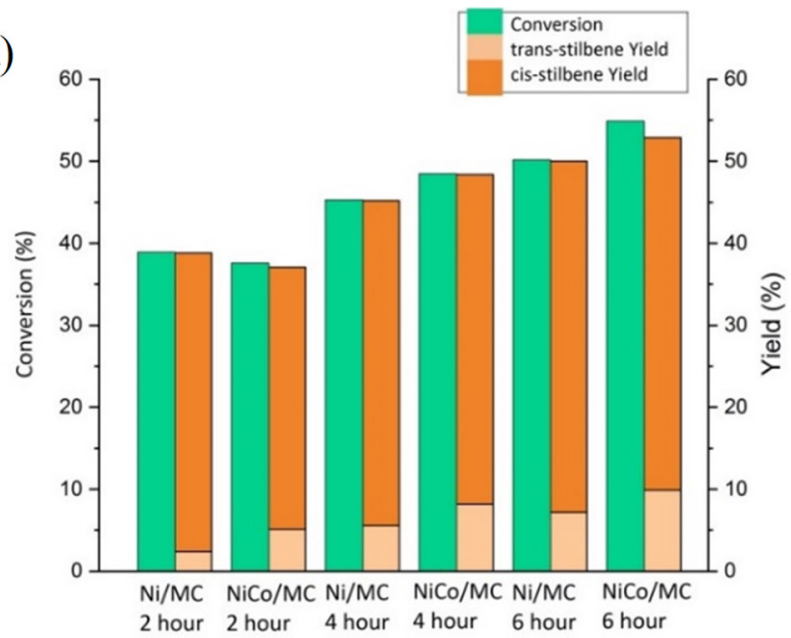

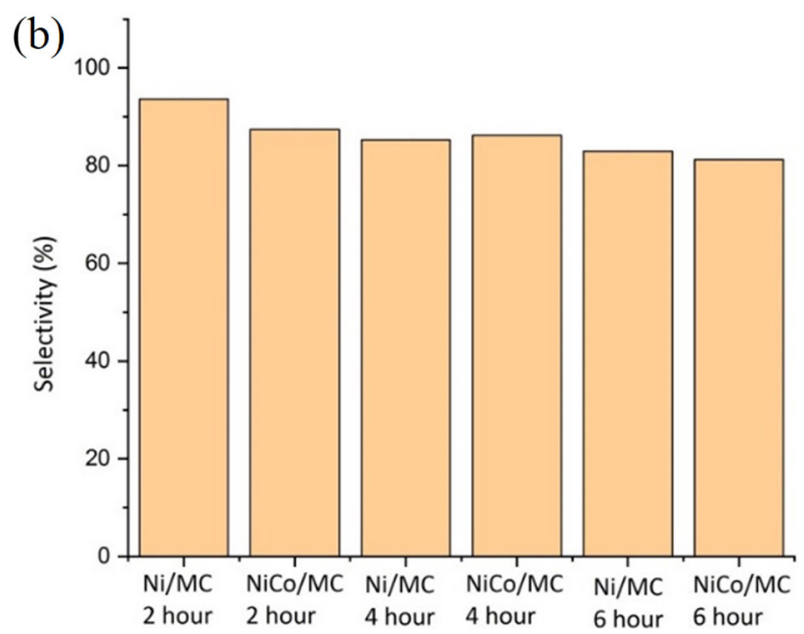

Figure 9. Hydrogenation of diphenylacetylene at room temperature with time variations: (a) diphenylacetylene conversion and yield of products, (b) selectivity of cis-stilbene. 
there was a slight decrease in selectivity towards cis-stilbene formation (Figure 9b). It can be understood that as the reaction time goes on, more methanol is activated by the borohydride, thus allowing the addition of the alkyne bond from two different sides to form a trans-stilbene product.

The effect of reaction temperature on the catalytic activity and selectivity of Ni/MC and NiCo/MC was investigated. The reactions were conducted for $4 \mathrm{~h}$. As predicted, there is an increase in the amount of diphenylacetylene converted as reaction temperature raised to $50^{\circ} \mathrm{C}$ (Figure 10a). An increment in the selectivity to cis-stilbene over the increase of reaction temperature is also observed (Figure 10b). Interestingly, the $\mathrm{NiCo} / \mathrm{MC}$ gave superior catalytic activity compared to $\mathrm{Ni} / \mathrm{MC}$ at higher temperature $\left(50^{\circ} \mathrm{C}\right)$ while maintaining selectivity. The optimum conditions were obtained at $50{ }^{\circ} \mathrm{C}$ for $4 \mathrm{~h}$ with a diphenylacetylene conversion of $71.5 \%$ with a selectivity to the cis-stilbene formation of $87.1 \%$. The presence of Co in the NiCo bimetal catalyst helped to improve the performance of the catalyst due to the high catalytic activity of cobalt and increased the adsorption capacity of borohydride anions on the surface of the catalyst to form active hydrogen which would interact with the alkyne [24]. These results indicate that the bimetallic NiCo/MC catalyst has promising catalytic activity in the selective hydrogenation of diphenylacetylene. In fact, its catalytic activity can also be compared with the performance of other Ni-based heterogeneous catalysts, or with homogeneous catalysts which generally use high hydrogen gas pressure, as summarized in Table 2.

(a)

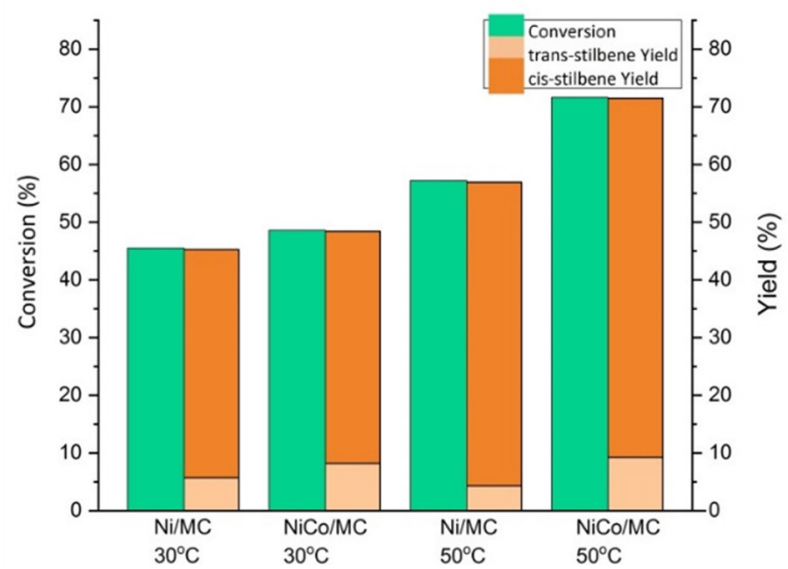

(b)

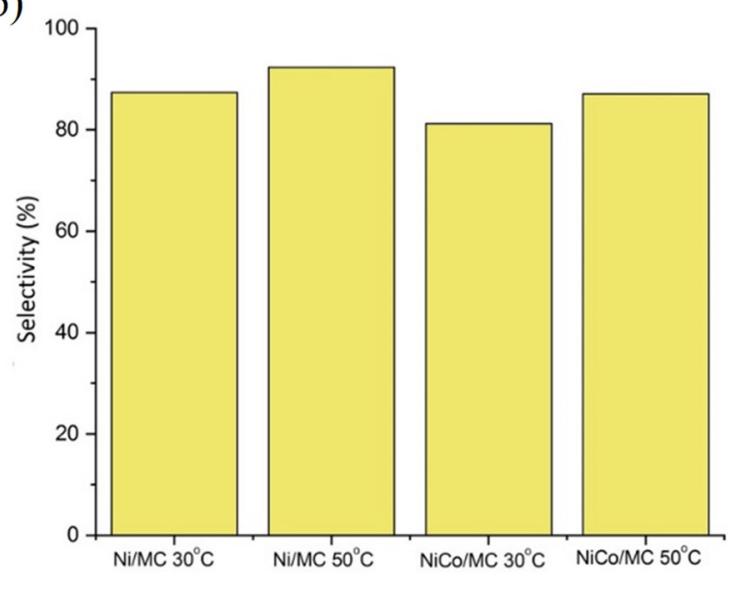

Figure 10. Hydrogenation of diphenylacetylene with variation of temperature reaction: (a) diphenylacetylene conversion and yield of products, (b) selectivity of cis-stilbene.

Table 2. The catalytic activity of NiCo/MC compared to other Ni-based catalysts in the hydrogenation of diphenylacetylene.

\begin{tabular}{|c|c|c|c|}
\hline Catalyst & Conditions & Results & Ref. \\
\hline $\begin{array}{l}\mathrm{Ni}\left(\mathrm{NO}_{3}\right)_{2} \cdot 6 \mathrm{H}_{2} \mathrm{O} \\
\text { monodentate P-ligand } \\
\text { (homogeneous) }\end{array}$ & $\begin{array}{l}120^{\circ} \mathrm{C}, 30 \text { bar } \mathrm{H}_{2}, \mathrm{CH}_{3} \mathrm{CN} \\
\text { solvent, } 15 \mathrm{~h}\end{array}$ & $\begin{array}{l}\text { Conversion: } 90 \%-98 \% \\
\text { Selectivity: } 87 \%-94 \%(Z) \text {-stilbene, }<1 \%(E) \text {-stilbene }\end{array}$ & {$[5]$} \\
\hline $\begin{array}{l}\mathrm{NiCl}_{2} \\
\text { (colloidal Ni NP) }\end{array}$ & $\begin{array}{l}\text { Room temperature, } \mathrm{NaBH}_{4} \\
\text { ( } 2 \text { equiv.), } \mathrm{MeOH} \text { solvent }\end{array}$ & $\begin{array}{l}\text { Conversion: } 98 \% \\
\text { Selectivity: } 94 \%(Z) \text {-stilbene, 5\% (E)-stilbene }\end{array}$ & {$[4]$} \\
\hline $\begin{array}{l}\text { Bimetallic } \mathrm{NiOs}_{4} \\
\text { (colloidal nanoparticle) }\end{array}$ & $\begin{array}{l}80^{\circ} \mathrm{C}, 10 \text { bar } \mathrm{H}_{2}, \\
\text { THF solvent, } 6 \mathrm{~h}\end{array}$ & $\begin{array}{l}\text { Conversion: } \sim 99 \% \\
\text { Selectivity: } \sim 83 \% \text { (Z)-stilbene, } \sim 14 \% \text { (E)-stilbene, } ~ 3 \% \text { diphenylethane }\end{array}$ & {$[25]$} \\
\hline $\begin{array}{l}\text { Ni@Y-Zeolite } \\
\text { (heterogeneous) }\end{array}$ & $\begin{array}{l}175^{\circ} \mathrm{C}, 10 \text { bar } \mathrm{H}_{2}, \\
\text { cyclohexane solvent, } 6 \mathrm{~h}\end{array}$ & $\begin{array}{l}\text { Conversion of : } 99 \% \\
\text { Selectivity: } 61 \%(\mathrm{Z}) \text {-stilbene, } 39 \% \text { (E)-stilbene }\end{array}$ & {$[26]$} \\
\hline $\begin{array}{l}\mathrm{Ni} \text {-fructose@SiO } \\
\text { (heterogeneous) }\end{array}$ & $\begin{array}{l}110^{\circ} \mathrm{C}, 10 \text { bar } \mathrm{H}_{2}, \\
\mathrm{CH}_{3} \mathrm{CN} \text { solvent, } 15 \mathrm{~h}\end{array}$ & $\begin{array}{l}\text { Conversion: }>99 \% \\
\text { Selectivity: } 93 \%(Z) \text {-stilbene, }<1 \% \text { (E)-stilbene, } 5 \% \text { diphenylethane }\end{array}$ & {$[27]$} \\
\hline $\begin{array}{l}\mathrm{NiCo} / \mathrm{MC} \\
\text { (heterogeneous) }\end{array}$ & $\begin{array}{l}50^{\circ} \mathrm{C}, \mathrm{NaBH}_{4}(2 \text { equiv. }) \\
\mathrm{MeOH} \text { solvent, } 4 \mathrm{~h}\end{array}$ & $\begin{array}{l}\text { Conversion: } 71.5 \% \\
\text { Selectivity: } 87.1 \%(\mathrm{Z}) \text {-stilbene, } 12.9 \%(\mathrm{E}) \text {-stilbene }\end{array}$ & $\begin{array}{l}\text { This } \\
\text { work }\end{array}$ \\
\hline
\end{tabular}




\section{Conclusion}

Selective hydrogenation of diphenylacetylene over Ni/MC and NiCo/MC catalysts was successfully carried out. The catalysts show good catalytic activity and selectivity for cis-stilbene as a major product. The presence of cobalt metal in the bimetallic $\mathrm{NiCo} / \mathrm{MC}$ significantly improves the catalytic activity at mild temperature while maintaining its good selectivity to $c i s$-stilbene.

\section{Acknowledgment}

This work was funded by the University of Indonesia (Universitas Indonesia) through PUTI Research Grant with contract number NKB-4550/UN2.RST/HKP.05.00/2020.

\section{References}

1. Ritleng V, Sirlin C, Pfeffer M. Ru-, Rh-, and Pd-catalyzed C-C bond formation involving C-H activation and addition on unsaturated substrates: Reactions and mechanistic aspects. Chemical Reviews 2002; 102 (5): 1731-1769. doi: 10.1021/cr0104330

2. Kani I, Unver H (2020). Bimetallic Ni(II) complex with carboxylate bridging for homogeneous hydrogenation of alkenes with $\mathrm{NaBH}_{4}$. Polyhedron 2020; 187. doi: 10.1016/j.poly.2020.114649

3. Özkar S, Zahmakiran M. Hydrogen generation from hydrolysis of sodium borohydride using $\mathrm{Ru}(0)$ nanoclusters as catalyst. Journal of Alloys and Compounds 2005; 404-406: 728-731. doi: 10.1016/j.jallcom.2004.10.084

4. Wen X, Shi X, Qiao X, Wu Z, Bai G. Ligand-free nickel-catalyzed semihydrogenation of alkynes with sodium borohydride: a highly efficient and selective process for cis-alkenes under ambient conditions. Chemical Communications 2017; 53 (39): 5372-5375. doi: $10.1039 / \mathrm{c} 7 \mathrm{cc} 02140 \mathrm{~b}$

5. Murugesan K, Bheeter CB, Linnebank PR, Spannenberg A, Reek JNH et al. Nickel-Catalyzed Stereodivergent Synthesis of E- and Z-Alkenes by Hydrogenation of Alkynes. ChemSusChem 2019; 12 (14): 3363-3369. doi: 10.1002/cssc.201900784

6. Alruqi SS, Al-Thabaiti SA, Khan Z. Iron-nickel bimetallic nanoparticles: surfactant assisted synthesis and their catalytic activities. Journal of Molecular Liquids 2019; 282: 448-455. doi: 10.1016/j.molliq.2019.03.021

7. Rodiansono R., Dewi AM, Husain S, Nugroho A, Sutomo S. Selective Conversion of 2-Methylfuran to 1,4-Pentanediol Catalyzed by Bimetallic Ni-Sn Alloy. Bulletin of Chemical Reaction Engineering \& Catalysis 2019; 14 (3): 529-541. doi: 10.9767/bcrec.14.3.4347.529-541

8. Seethapathy V, Sudarsan P, Pandey AK, Pandiyan A, Kumar THV et al. Synergistic effect of bimetallic Cu:Ni nanoparticles for the efficient catalytic conversion of 4-nitrophenol. New Journal of Chemistry 2019; 43: 3180-3187. doi: 10.1039/C8NJ05649H

9. Khairani NS, Abdullah I, Krisnandi YK. Synthesis and characterization of NiZn/mesoporous carbon as heterogeneous catalyst for carboxylation reaction of acetylene with CO2. AIP Conference Proceedings 2020; 2242 (1): 040039. doi: 10.1063/5.0007890

10. Gallo A, Snider JL, Sokaras D, Nordlund D, Kroll T et al. $\mathrm{Ni}_{5} \mathrm{Ga}_{3}$ catalysts for $\mathrm{CO}_{2}$ reduction to methanol: Exploring the role of Ga surface oxidation/reduction on catalytic activity. Applied Catalysis B: Environmental 2020; 267: 118369. doi: 10.1016/j.apcatb.2019.118369

11. Pei GX, Liu XY, Wang A, Su Y, Li L et al. Selective hydrogenation of acetylene in an ethylene-rich stream over silica supported Ag-Ni bimetallic catalysts. Applied Catalysis A: General 2017; 545: 90-96. doi: 10.1016/j.apcata.2017.07.041

12. Bian Z, Das S, Wai MH, Hongmanorom P, Kawi S. A Review on Bimetallic Nickel-Based Catalysts for $\mathrm{CO}_{2}$ Reforming of Methane. ChemPhysChem 2017; 18 (22): 3117-3134. doi: 10.1002/cphc.201700529

13. Yang L, Yu S, Peng C, Fang X, Cheng Z et al. Semihydrogenation of phenylacetylene over nonprecious Ni-based catalysts supported on AlSBA-15. Journal of Catalysis 2019; 370: 310-320. doi: 10.1016/j.jcat.2019.01.012

14. Ridwan M, Suhanda D, Aziz I, Abdullah I. Dehydrogenation of hydrazine hydrate using NiCo bimetallic catalyst supported on natural zeolite (ZA), Z-NaY, Z-HY, $\mathrm{Al}_{2} \mathrm{O}_{3}$ and $\mathrm{TiO}_{2}$. Rasayan Journal of Chemistry 2021; 14 (3): 1821-1828. doi: 10.31788/RJC.2021.1436319

15. Pal N, Bhaumik A. Soft templating strategies for the synthesis of mesoporous materials: Inorganic, organic-inorganic hybrid and purely organic solids. Advances in Colloid and Interface Science 2013; 189-190: 21-41. doi: 10.1016/j.cis.2012.12.002

16. Afriani A, Abdullah I, Krisnandi YK. Synthesis of $\mathrm{NiCl}_{2}$ impregnated mesoporous carbon and its adsorption activity on $\mathrm{CO}_{2}$. AIP Conference Proceedings 2021; 2349: 020048. doi: 10.1063/5.0051524

17. Abdullah I, Andriyanti R, Nurani DA, Krisnandi YK. Nickel-phenanthroline complex supported on mesoporous carbon as a catalyst for carboxylation under $\mathrm{CO}_{2}$ atmosphere. Bulletin of Chemical Reaction Engineering \& Catalysis 2021; 16 (1): 111-119. doi: 10.9767/ bcrec.16.1.9733.111-119

18. Pamungkas AZ, Abdullah I, Krisnandi YK. Synthesis and characterization of Ni nanoparticles supported on nitrogen-doped mesoporous carbon. IOP Conference Series 2019; 496: 012003. doi:10.1088/1757-899X/496/1/012003 
19. Amalia PN, Abdullah I, Rahayu DUC, Krisnandi YK. Synthesis and Characterization of Copper Impregnated Mesoporous Carbon as Heterogeneous Catalyst for Phenylacetylene Carboxylation with Carbon Dioxide. Indonesian Journal of Chemistry $2021 ; 21$ (1): $77-87$. doi: $10.22146 /$ ijc. 52778

20. Zawislak A, Choma J, Jaroniec M. Adsorption and structural properties of soft-templated mesoporous carbons obtained by carbonization at different temperatures and KOH activation. Applied Surface Science 2010; 256: 5187-5190. doi: 10.1016/j.apsusc.2009.12.092

21. Sulistianti I, Krisnandi YK, Moenandar I. Study of $\mathrm{CO}_{2}$ adsorption capacity of mesoporous carbon and activated carbon modified by triethylenetetramine (TETA). IOP Conference Series: Materials Science and Engineering 2017; 188, 012041. doi: 10.1088/1757899X/188/1/012041

22. He X, Xu Y, Yao X, Zhang C, Pu Y et al. Large exchange bias and enhanced coercivity in strongly-coupled Ni/NiO binary nanoparticles. RSC Advances 2019; 9 (52): 30195-30206. doi: 10.1039/C9RA03242H

23. García T, Murillo R, Agouram S, Dejoz A, Lázaro MJ et al. Highly dispersed encapsulated AuPd nanoparticles on ordered mesoporous carbons for the direct synthesis of $\mathrm{H}_{2} \mathrm{O}_{2}$ from molecular oxygen and hydrogen. Chemical Communications 2012; 48 (43): 5316-5318. doi: $10.1039 / \mathrm{c} 2 \mathrm{cc} 14667 \mathrm{c}$

24. Netskina OV, Tayban ES, Rogov VA, Ozerova AM, Mukha SA et al. Solid-state $\mathrm{NaBH}_{4}$ composites for hydrogen generation: Catalytic activity of nickel and cobalt catalysts. International Journal of Hydrogen Energy 2021; 46 (7): 5459-5471. doi: 10.1016/j.ijhydene.2020.11.078

25. Egeberg A, Dietrich C, Kind C, Popescu R, Gerthsen D et al. Bimetallic $\mathrm{NiIr}_{4}$ and $\mathrm{NiOs}_{4}$ alloy nanoparticles and their catalytic performance in hydrogenation reactions. ChemCatChem 2017; 9 (18): 3534-3543. doi: 10.1002/cctc.201700168

26. Deng X, Bai R, Chai Y, Hu Z, Guan N et al. Homogeneous-like alkyne selective hydrogenation catalyzed by cationic nickel confined in zeolite. Chinese Chemical Society Chemistry 2021; 3: 1101-1114. doi: 10.31635/ccschem.021.202100820

27. Murugesan K, Alshammari AS, Sohail M, Beller M, Jagadeesh RV. Monodisperse nickel-nanoparticles for stereo- and chemoselective hydrogenation of alkynes to alkenes. Journal of Catalysis 2019; 370: 372-377. doi: 10.1016/j.jcat.2018.12.018 